\title{
Tiempo, memoria e identidad personal
}

ÁlVARO PAZOS

Universidad Autónoma de Madrid

\section{RESUMEN}

En el análisis de los relatos orales y escritos de los antiguos niños españoles evacuados a la URSS durante la Guerra de España, el autor intenta problematizar el modo como tiempo, memoria e identidad personal se entrelazan en tales relatos, proponiendo un acercamiento sociológico, relativamente autónomo respecto del que podría hacer la historia o la psicología. El análisis pone de manifiesto que la dinámica subjetiva en la que se contextualizan los discursos de estas personas - los modos de hablar sobre el pasado, el presente, el futuro, la vida, etc.- define estos discursos, no tanto por la coherencia o el logro o el intento de conseguir una unidad sintética, una narración bien estructurada sacada de una memoria individual sobre el pasado, cuanto por las disrupciones, contradicciones y aporías en las que con frecuencia divaga y se demora el relato, elementos todos que remiten a la problemática social y subjetiva del presente de estos antiguos niños.

Palabras clave: Guerra Civil Española, Unión Soviética, Recuerdos personales, Discursos autobiográficos, Memoria, Identidad Personal.

\section{SUMMARY}

In his analysis of the oral and written narratives by the former children evacuated to the Soviet Union during the Spanish Civil War, the author reflects on the manner in which time, memory and personal identity interrelate in these accounts. He proposes a sociological approach to the subject, comparatively more independent than that of history or psychology. His analysis reveals that the subjective dynamics that contextualizes the discourses of these people - the manner in which they talk about the past, the present, the future, life and so forth- defines these discourses in terms not so much of coherence or attempt of achievement of a synthetic unity, a well-structured narrative drawn from an individual remembrance of the past, as of disruptions, contradictions and aporias that make the narratives disorganized and uneven-which is characteristic of the present social and subjective conditions of these former children.

Key words: Spanish Civil War, Soviet Union, Remembrances, Autobiographical Discourses, Memory, Personal Identity.

RDTP, LIX, 1 (2004): 189-202 
La interrelación entre los conceptos que dan título a este ensayo (tiempo, memoria, identidad personal) la voy a enfocar desde una perspectiva antropológico-social, retomando datos de una investigación, en la que participo, sobre los "niños españoles" evacuados a la URSS durante la Guerra Civil española (Devillard, Pazos, Castillo y Medina 2001). El objeto de interés de dicho trabajo reside en las formas de producción discursiva de identidad y subjetividad; se ha centrado en los modos como se presentaban los sujetos sociales en ese traslado del tiempo vivido al discurso que suponen los relatos autobiográficos.

Durante la Guerra Civil española, se organizaron cuatro expediciones de evacuación de niños con destino a la Unión Soviética desde zonas republicanas. Aproximadamente 2.900 niños de entre 3 y 15 años (oficialmente, entre 5 y 12 años) partieron en esas expediciones. En un principio se pensó que la estancia allí sería breve, pero la victoria de Franco y los sucesos posteriores (la II Guerra Mundial, la ruptura de relaciones entre España y la URSS, etc.) dilataron el periodo. Llegados a la Unión Soviética, los niños fueron alojados en "Casas de Niños", instituciones especialmente creadas para ellos, en las que residieron y fueron educados. En 1941, al entrar las tropas alemanas en la URSS, sufrieron una segunda evacuación. En 1956 y 1957, los acuerdos entre las autoridades españolas y soviéticas permitieron el retorno de buena parte de ellos. Pero esta repatriación marca una especie de escisión en las trayectorias de los miembros del colectivo: unos regresaron en ese momento a España (de los cuales algunos volverían más tarde a la URSS), otros se quedaron allí y regresarían a España más tarde (a finales de los setenta o ya en los años noventa); y otros, por último, viven en Rusia todavía. El repaso más somero de la historia de estos "niños españoles" muestra, en suma, que no se trata -a pesar de lo que aparece en muchas imágenes y discursos (mantenidos en ocasiones por ellos mismos)- de un colectivo homogéneo. Las trayectorias divergen y se reúnen en distintos momentos de la historia, se van constituyendo grupos diferentes dentro del colectivo y, en el límite, uno se encuentra con itinerarios o experiencias radicalmente singulares.

Las reflexiones que propongo tienen su punto de partida en un interés, en principio bastante limitado, por el uso de relatos e historias de vida en las ciencias sociales. En otro trabajo (Pazos 2002) he considerado críticamente el tratamiento por parte de éstas del material autobiográfico; en síntesis, intenté mostrar entonces el valor de una perspectiva no textualista de este material, atenta a la dispersión de actos de habla que constituyen los discursos autobiográficos y a la presencia en ellos de formas no narrativas del recuerdo. Con frecuencia, el análisis de relatos de vida da por supuesta una narratividad panhumana y omnipresente: narrar aparece como un modo fundamental de eficacia simbólica, de constitución básica y originaria de la ex- 
periencia humana. Los problemas que, advertida o inadvertidamente, derivan de estos presupuestos son numerosos y tienen que ver tanto con el hecho de que la vida nunca discurre de acuerdo con el orden y el argumento que el relato le proporciona - a lo que apuntan conceptos como el de "ilusión biográfica" de Bourdieu (1997) o el de "ideología biográfica" de Bertaux (1997) - como con la constatación de la falta de unidad de unos relatos que, especialmente cuando son orales, se dispersan en líneas narrativas, pero también en suspensiones y fracturas de esas líneas, manifestando una búsqueda y/o unos procesos de significación que no responden sólo a pulsiones narrativas (Lejeune 1996).

Considerados los heterogéneos discursos autobiográficos como narraciones unitarias, no queda sino practicar algun tipo de morfología: diferenciar entre unas y otras formas de relatar-recordar la propia vida, de dibujar las trayectorias y distribuir los acontecimientos (en líneas ascendentes o descendentes, de progreso o de caída, a uno y otro lado de un corte capital, etc.). El relato de vida de un sujeto puede quedar así reducido a una especie de tipo ideal. En los estudios de psicología inspirados por la obra de Jerome Bruner o Kenneth Gergen, se aprecia esta manera de trabajar (véanse, por ejemplo, algunos de los trabajos recopilados por Rosa, Bellelli y Bakhurst (2000); y por Páez, Valencia, Pennebaker, Rimé y Jodelet 1998). Lo más que se puede hacer, entonces, es correlacionar las formas de memoria-narración con el lugar que ocupan los sujetos en las estructuras sociales; pero no se podrá indagar en el modo como esta ubicación social condiciona realmente la producción del discurso ni en las situaciones de producción, los efectos de su enunciación y su dispersión interna.

Ensayaré aquí algunas notas sobre las condiciones sociales de producción y recepción de las formas narrativas, así como los usos políticos (en un sentido general) de las narraciones autobiográficas. La dinámica discursiva autobiográfica no puede remitirse a una función narrativa originaria, porque las narraciones se producen y se usan en ocasiones determinadas, siguen unos $\mathrm{u}$ otros trazados dependiendo también de circunstancias determinadas, y son utilizadas retóricamente por agentes sociales específicos. Cualquiera de las formas de contar que se pueden entresacar, por ejemplo, de los discursos de los "niños españoles" - formas que pretenden sintetizar los sesenta años transcurridos- es algo que se hace imprescindible asociar a las situaciones prácticas, discursivas y extradiscursivas, en las que la actividad de recordar desempeña funciones sociales. Tomemos, como ilustración, dos modelos, harto frecuentes, que fácilmente podrían figurar como tipos ideales. Está, de un lado, la historia de los "niños españoles" contada al investigador como una historia marcada por una "infancia rota", como una tragedia permanente y permanentemente determinada por la ruptura que desde el momento de la 
evacuación los convirtió en "víctimas", en "niños de la guerra". Es un relato que pasa por encima de los largos años intermedios y une la salida con el regreso actual; un regreso también dramático, por la falta de atención de las administraciones española o rusa, por los problemas para solucionar el tipo de vivienda, las pensiones, la ciudadanía de cónyuges o familiares... De otro lado, esta forma narrativa contrasta con la que presenta la estancia infantil en la URSS como "el período más feliz de la vida", que ha marcado a los sujetos, que ha forjado vínculos muy fuertes con la Unión Soviética, con su pueblo o su historia; se narrará, entonces, la historia no de unas "víctimas", sino de unos "protagonistas" activos, centrada no en los temas de la "ausencia" o la "ruptura", sino en la continuidad de los lazos.

Se trata, en uno y en otro caso, de retóricas concretamente realizadas en contextos específicos, con significaciones diversas porque operan de acuerdo con intereses también específicos y variables, puestas en acto por agentes sociales y con efectos performativos de diversa índole. Así, en nuestra investigación hemos abordado el proceso de construcción y los contextos de surgimiento, para los "niños españoles", de la categoría "niños de la guerra" (Devillard et alii 2001: 37-75). Para ello, revisamos y analizamos noticias periodísticas relativas al colectivo que aparecen en momentos fundamentales de la trayectoria de éste desde su salida de España. Se muestra ahí que las diversas y divergentes imágenes del colectivo e interpretaciones de los sucesos de su historia se transmiten en retóricas que el análisis debe ubicar, atendiendo tanto a las circunstancias sociales y políticas como a las instancias que las activan. La presencia de una misma retórica en momentos diferentes y en boca de actores diferentes, lleva a preguntarse por la disparidad de significaciones que subyace a una forma de contar la historia. En 1987 y 1988, por ejemplo, coincidiendo con las conmemoraciones de su salida de España, algunos medios periodísticos ofrecieron una versión particular de la historia de los que entonces (pero no antes) fueron llamados "niños de la guerra": se les hizo "víctimas" "involuntarias" del "exilio" "infantil", centrándose únicamente en el momento de la evacuación de la infancia como algo que fijaría para siempre su identidad y problemática. Es uno de los agenciamientos de la primera forma de relato que mencionaba más arriba; forma que volvió a aparecer en los medios de comunicación durante los años noventa, en paralelo - reforzándose mutuamente- al tratamiento de los "niños de la guerra" actuales. En todos estos casos, el referente de los discursos es el colectivo de "niños" que regresan en ese momento a España; y son también miembros de este colectivo quienes cuentan así su historia. Esto en un contexto en el que lo que está en juego son demandas y reivindicaciones concretas (pensiones, ciudadanía, residencia...) que los que regresan plantean a las Administraciones, y en el que esa narrativa podía legitimarlos ideológicamente como "españoles"; pero igualmente en un con- 
texto que ve crecer —en periódicos, aunque también en revistas y programas televisivos de corte sensacionalista - el tratamiento despolitizado y humanitario de la historia de los "niños españoles" (como, por lo demás, el tratamiento despolitizado y humanitario de la Guerra Civil, el exilio, etc.).

De otro lado, por las mismas fechas, hubo apariciones de los "niños españoles" que presentaban otra versión, según la segunda forma apuntada más arriba. En el trabajo nuestro citado (Devillard et alii 2001: 56-59) se analiza un reportaje de la revista Cambio 16, en mayo de 1987, especialmente ilustrativo, en el que un grupo de "niños", con trayectorias y problemáticas diferentes a las del grupo anterior (en este caso, hay personas que se repatriaron en 1956-1957), exponen una ficción que, en contra de la imagen de la "infancia rota", enfatiza la continuidad, subraya los factores políticos de la contienda, expresa el agradecimiento al país e incluso el régimen que les había acogido, se detiene en los acontecimientos posteriores a la evacuación y su participación en ellos, rememora el regreso al país de origen y el trato discriminatorio al que fueron sometidos por el régimen franquista; en definitiva, ofrece una narración en la que los "niños españoles", lejos de ser "víctimas involuntarias" son sujetos activos y políticos de la historia. Es éste un discurso, por lo demás, que aparece con frecuencia en nuestras entrevistas con quienes regresaron en 1956 y 1957; refuerza sus tonos reivindicativos de una imagen positiva del colectivo cuando explícitamente se plantea como respuesta a la interpretación que - a través de los medios de comunicación, por ejemplo- pueden ofrecer algunos de los que regresan ahora de Rusia. La narración está, entonces, determinada hasta cierto punto por un intento de responder - a veces públicamente- a interpretaciones de su historia, que se entiende que son injustas o parciales.

Creo que la reflexión sobre tiempo, memoria e identidad personal, que se lleva a cabo en la actualidad en muy diferentes frentes, debería ocuparse y sacar todas sus consecuencias de los relatos en ejercicio contrapuestos o divergentes que el análisis sociológico puede revelar. En este sentido, y teniendo en cuenta un contraste de retóricas como el que acabo de señalar, me parece que son varias las cuestiones a meditar; relativas tanto al tipo de análisis de la relación entre memoria individual y memoria colectiva que conviene llevar a cabo - al modo de articular el eje memoria-identidad personal-, como a las dimensiones éticas y políticas del ejercicio y de la transmisión de la memoria en la sociedad "occidental" contemporánea.

\section{MEMORIA SOCIAL}

Un primer punto de reflexión lo suscita la relación entre memoria individual y memoria colectiva. Probablemente, la misma distinción analítica entre 
una y otra no tenga demasiado sentido. Desde luego, el estudio de casos como el de los "niños españoles" apoyaría la noción de una memoria que es siempre social: el recuerdo individual, que es expresión discursiva de identidad y subjetividad, es aquí desde el principio público. Y lo es, en primer lugar, porque se juega constantemente con una identificación del "yo" y el "nosotros". En ocasiones, los enunciados cambian de manera explícita de sujeto, o concluyen generalizando a partir de lo que era una experiencia singular. Pero el recuerdo es también público en el sentido de que muchas veces es, con gran evidencia, una construcción colectiva. Las personas parecen apropiarse de, o incorporar, sucesos o imágenes que no han vivido o visto directamente. Hay una especie de folklore de los "niños españoles" que consta de anécdotas que encontramos aquí y allá expresadas en los mismos términos: como el viaje en barco hasta Leningrado, lleno de referencias iguales al color blanco "como las gaviotas" de la embarcación, o el paso por aguas alemanas "tan malas como ellos". La llegada a Leningrado y el apoteósico recibimiento se narran en los mismos términos. Las experiencias durante la II Guerra Mundial, o el interrogatorio al que fueron sometidos en Madrid los que regresaron en 1956 y 1957, son también ejemplos ilustrativos.

De una manera más general, todo discurso subjetivo es público, en la medida en que ocupa un lugar dentro de un "espacio de puntos de vista" (Bourdieu 1999: 9). Al contrario de una aproximación textualista, el análisis pragmatista de los discursos autobiográficos se ocupa de los lugares en los que se produce el decir, del modo como cada sujeto construye un punto de vista que se define y adquiere sentido estructuralmente, esto es, por las relaciones que pueden establecerse entre ese punto de vista, esa versión de la historia, con otros puntos o versiones (las de otros "niños", o de periodistas, o de la Administración, o de los Partidos, o de los investigadores...). El análisis intentará restablecer, entonces, dicho "espacio", en el que los discursos de las memorias individuales, por sus relaciones mutuas de semejanza o diferencia, muestran su naturaleza social.

Tal "espacio" es, por supuesto, una herramienta creada por el investigador para hacer inteligibles los significados de los relatos, aunque es cierto que en circunstancias reales es posible presenciar el contraste y el conflicto, el apoyo y el refuerzo de varios puntos de vista, como ilustran las dos retóricas evocadas más arriba. Por otra parte, la semejanza y/o diferencia entre puntos de vista no puede entenderse como una relación meramente dialéctica y relativa sólo a los enunciados. Emitidos por agentes sociales concretos y situados —que tienen un pasado que no es sólo objeto de su recuerdo sino que los constituye como tales-, los discursos remiten a las trayectorias históricas, también convergentes y/o divergentes, de los sujetos.

Esta situación dentro de un espacio social se manifiesta, en todo caso, 
en la estructura dialógica del discurso; éste no es el producto monológico de un sujeto. En los relatos de vida aparecen voces distintas: ya sea como preámbulo ("a ustedes les habrán dicho que..."), ya sea en la estructura dialogal que se le da ("me dijo... y yo le dije..."), ya sea asumiendo tácitamente otros puntos de vista, para cuestionarlos o para relativizar el propio. Sólo se entiende, entonces, lo que un sujeto dice si se restablece la posición del interlocutor con el que realmente dialoga, que no es siempre el entrevistador. En este sentido, el recuerdo individual es público, es social, porque parece exponerse pública o socialmente siempre, aunque se emita en el contexto de una entrevista, como si tuviera efectos fuera, más allá de ella.

\section{MEMORIA Y SUBJETIVIDAD}

No habría que pensar en las convergencias y divergencias de puntos de vista sobre la historia como algo "exterior" a los sujetos. En nuestra investigación sobre los "niños españoles", hemos insistido en que dentro de un mismo relato de vida surgen elementos de una u otra línea narrativa, dependiendo de diversas variables que son relativas, en principio, al contexto discursivo (si es la presentación en los momentos iniciales, o son referencias que se hacen en momentos confidenciales, o al desarrollar ciertos temas...): la exposición de la estancia en las "Casas de Niños", por ejemplo, como "el período más feliz de mi vida" es algo recurrente en casi todos los relatos orales, ya se haga un balance positivo o negativo de la propia vida. Una persona puede presentar inicialmente una historia "victimista", teniendo muy presente sus demandas ante la Administración; pero, más tarde, comentando el caso de las declaraciones realizadas por uno de sus compañeros en los media y que pueden interpretarse como "antisoviéticas", esboza los rasgos de la versión contraria.

La relación con el pasado no es unidireccional ni unidimensional. En rigor, al hablar de relación con el pasado de un sujeto no hay que entender ni una sola relación ni un solo pasado. Hay pasados diversos, cualitativamente distintos (difícilmente integrables en una continuidad) y con los que se mantienen diferentes lazos. La situación de todo sujeto, su articulación subjetiva, se caracteriza por adhesiones a menudo conflictivas; los discursos autobiográficos no parecen constituir identidades, asociadas a trayectorias narrativas, sino desplegar problemáticas socio-subjetivas.

No todos los vínculos con los pasados se expresan narrativamente. A lo largo de las entrevistas en profundidad, el ejercicio de la memoria rompe con frecuencia cualquier orden cronológico y surgen otras lógicas, constitutivas sin duda de una subjetividad no reducible a identidad narrativa: anécdotas que bajo apariencia de relatos son realmente escenas evocadas, situacio- 
nes o encuentros esporádicos, imágenes de personas que uno vio una vez, frases que escuchó cuyo significado no alcanza a restablecerse, que quedan como colgando en el relato, sin resolución. Más frecuente aún entre los "niños españoles" es la evocación subjetiva de las cosas que perdieron o que les quitaron, como los vestidos con que llegaron a la URSS, los juguetes, o los libros con que estudiaron... O las repentinas impresiones que cortan tantas veces el desarrollo del discurso: el olor de una habitación, el calor o el frío, el sabor de la comida rusa, los colores y la exuberancia de los bosques en torno a la "Casa"...

En todos estos casos, el recuerdo no elabora tramas argumentativas. El ejercicio distendido de la memoria se entrega a ensoñaciones ligadas por asociación, a veces aparentemente gratuitas, siempre expresiones del lazo tan extraño, no relatable, que une al pasado. Son como huellas que quedan dibujadas en el transcurso de la conversación y que, como dice Augé, están "desconectadas de todo relato posible o creíble", "se han desligado del recuerdo" (Augé 1998: 30). Si la trama dispone, como el calendario, marcas en el tiempo, hay una experiencia del tiempo en estos discursos, o la experiencia de un tiempo, que no es del calendario ni de la trama: un "tiempo sin medida". Con razón evoca Augé la escritura surrealista: hay una lógica que, a pesar de su carácter discursivo, está cerca de la del sueño, pues mezcla tiempos - recorriéndolos en todos los sentidos-, crea extrañas simultaneidades y hace coexistir ritmos diferentes (Pontalis 1997: 17).

La retórica del sí mismo en los discursos autobiográficos no puede reducirse a la expresión de una identidad narrativa. La trabazón compleja entre pasado y presente, realidad y discurso, individuo y colectivo, explica que se dibujen imágenes varias de sí en un dialogismo interno que produce formas de subjetivación. Estas formas no se resuelven en un producto autobiográfico final, pues manifiestan la ambivalencia de los lazos que unen (y constituyen) al sujeto con los diversos pasados y con las dimensiones variables del presente.

\section{LA VERDAD DE LA MEMORIA}

Un tercer punto de reflexión se refiere a la cuestión de la verdad de la memoria, ineludible al trabajar con testimonios del pasado. Hay, como dice Ricoeur, una dimensión verista de la memoria: el traslado de la vivencia al discurso que el testimonio lleva a cabo es la primera expresión de la ambición de verdad de la memoria.

El testimonio tiene una enorme importancia en la vida social: en los tribunales, en la historia, pero sobre todo en la vida cotidiana. Es una categoría de la conversación: si preguntamos a-alguien quién es, nos contará una historia, la de su familia, 
etc. Nos contará algo que inspire confianza. Eso es un testimonio [...]. Yo quisiera insistir sobre esta expresión "aquello existió", pues al decir el testigo que "aquello existió", dice tres cosas a la vez. La primera es "yo estuve alli" [...]. Es mi afirmación, es la expresión de lo que viví, de lo que sufrí; es el logos de un pathos inicial. Pero el testigo dice también algo más, no solamente "yo estuve allí", sino también "créeme", esto es, apela a la confianza del otro, con lo cual el recuerdo entra en una relación fiduciaria [...]. Es entonces cuando el testigo dice una tercera cosa: agrega "y si no me crees, pregúntale a otro" [...]. El testimonio traslada las cosas vistas a las cosas dichas, a las cosas colocadas bajo la confianza que el uno tiene en la palabra del otro (Ricoeur 2002: 26-27).

Sin embargo, la indagación sociológica no aborda la categoría del testimonio fenomenológicamente, sino en agenciamientos históricos y en medio de problemáticas particulares. La presencia de diversos testimonios en liza invita a centrarse en las condiciones de verdad del testimonio en tanto que "cosa dicha" o, más bien, en tanto que "decir social". Siendo su objeto de interés la verdad de las luchas que tienen como enjeu, entre otros, la verdad (Bourdieu 1982: 16), al acceder a los testimonios no intentará el científico social restituir la verdad histórica a la que éstos apuntan y que ambicionan, sino las relaciones, las tensiones y los conflictos entre lo que son ficciones, más o menos verosímiles, que pugnan por la verdad. Si el testimonio es movimiento hacia la verdad del pasado, es también una enunciación que aspira a autorizar al sujeto que enuncia ("yo estuve alli"), apelando estratégicamente a una situación y a un(os) interlocutor(es) ("créeme"), a un medio o una instancia social de validación y legitimación ("pregúntale a otros"), y que, por todo ello, testifica eventualmente frente a o contra otros, llegando a desautorizar, en el mismo acto, otros testimonios. Por lo demás, estas dimensiones performativas no vienen definidas exclusivamente por las características esenciales de la situación (como "situación humana de comunicación"). La situación se compone a partir de una estructura y una distribución de poderes que permite a unos $\mathrm{u}$ otros (a unos, pero no a otros) emitir voces autorizadas, ser (o no) escuchados, dirigirse a éstos o aquéllos, y remitir (para la validación) a tales o cuales "otros". Las narrativas son performances (McLean 1988) y, como todo acto performativo, no guardan en sí mismas la magia de su enunciación, sino que ésta radica en las dimensiones sociales y políticas del acontecimiento (Bourdieu 2001).

Este enfoque, orientado hacia las condiciones sociales de verdad del testimonio, es especialmente pertinente en la actualidad, en un presente que apela con insistencia al "deber de memoria" y en el que la memoria, en sí y por sí misma, parece dotada de valor. La reparación de olvidos y la restitución de sucesos que los testimonios pretenden, en relación especialmente con el "totalitarismo" y el control o supresión de la memoria que los regímenes totalitarios habrían puesto en práctica sistemáticamente (Passerini 1992), ha derivado 
en un "elogio incondicional de la memoria" (Todorov 2000: 15). Memoria y olvido vienen a ser, con frecuencia, los dos polos contrapuestos ideológicamente del debate. Y, sin embargo, la restitución total como objeto de la memoria no es siquiera posible; memoria y olvido son, más bien, las dos caras de un proceso que es siempre selectivo. $\mathrm{Si}$, entonces, psicológica y sociológicamente el olvido no es mero fallo de la memoria sino componente esencial de ésta, también la reflexión ética y política sobre el "deber de memoria" ha de plantearse la afirmación contenida en un "deber de olvido". "Llevar a cabo el elogio del olvido no implica vilipendiar la memoria, y mucho menos ignorar el recuerdo, sino recordar el trabajo del olvido en la primera y detectar su presencia en el segundo. La memoria y el olvido guardan en cierto modo la misma relación que la vida y la muerte" (Augé 1998: 19).

En la obra citada, Todorov distingue entre el proceso de recuperación del pasado y el de utilización de la memoria. La evocación del pasado en el presente desempeña funciones sociales diversas en y para este presente. Es diferente el lugar del recuerdo (y del pasado) en sociedades sin escritura y en sociedades alfabetizadas; y lo es también en las diversas esferas de la vida de cualquier sociedad. Es preciso entonces considerar, caso por caso, los usos particulares, así como los "abusos de la memoria" en sociedades que, como la nuestra en el cambio de milenio, se obsesionan con la Memoria. Distinguir casos, buenos y malos usos de la memoria, y analizarlos en tanto que usos sociales, quiere decir que abandonamos la imagen antropomorfizada de una sociedad que recuerda, que olvida, que perdona, etc., al modo de una persona. Es un paso para entender que estas actividades son procesos sociales complejos cuando el sujeto es un colectivo, por lo que las demandas éticas (de memoria, de olvido, de perdón...) no pueden dirigirse a los colectivos como a los individuos, y deben, en el caso de aquéllos, traducirse en políticas de memoria y olvido.

Las colectividades históricas -estén o no organizadas como Estados- no son personas, razón por la cual no se les puede aplicar sin más, de manera acrítica e irreflexiva, las reglas morales por las que se rigen los individuos. La política es lo que los ingleses llaman un dirty business, un sucio asunto. El deber de memoria en política no puede tener el mismo sentido que el deber de memoria de las personas individuales (Schnapper 2002: 76).

\section{COMUNICACIÓN DE TESTIMONIOS}

La presentación en periódicos, programas televisivos y otros medios de comunicación de los "niños españoles" indica otro foco de reflexión, en torno, esta vez, a las condiciones sociales de comunicación de los testimonios. Primo Levi (1989: 114 y ss.) ha escudriñado en las complicaciones y parado- 
jas de la comunicación, de la comunicabilidad e incomunicabilidad que se les imponen dramáticamente en diferentes momentos de su vida a quienes vivieron experiencias como las de los campos de exterminio. Ahí se revelan situaciones vitales en que el reto no es meramente poder comunicar lo que ha sido silenciado. Como al hablar del recuerdo, parece adecuado también atender a los usos concretos, al ejercicio y a las modalidades de la comunicación.

Hay siempre una especie de fractura entre la intensidad propia de la experiencia vivida, e incluso recordada, y las lógicas con que se comunica públicamente esa experiencia. En el caso de los "niños españoles", como en otros, puede comprobarse con facilidad que en las versiones publicitadas por unos agentes sociales, para otros agentes siempre "falta algo". Además, sabemos que, a través de la comunicación reiterada, los relatos se simplifican, adoptan esquemas condensados repetidos al cabo como "historia oficial". Pero las limitaciones que el hecho comunicativo impone a la intensidad de lo vivido no son sólo genéricas; se trata de ver, más bien, qué limitaciones específicas imponen medios, también específicos, de comunicación.

La aparición, por ejemplo, en los medios de comunicación de masas amplifica de un modo peculiar la estandarización de los testimonios singulares, forzando el uso de determinadas estructuras retóricas y narrativas cuya lógica será importante en diferentes momentos analizar. En la retórica "humanitaria" de que hablábamos más arriba —que, aunque puede ser, como indiqué, activada por los sujetos con objetivos y de acuerdo a intereses propios, parece impuesta (o al menos facilitada y reforzada) por el medio mismo- hay lapsos fundamentales (y amplios) en que los relatos orales se detienen pormenorizadamente (como la estancia en las Casas de Niños, o las condiciones de la vida cotidiana en la URSS), pero que quedan fuera de los testimonios comunicados, en aras de una narración centrada en hitos dramáticos y dramatizables como la salida, la evacuación durante la Guerra Mundial o el emocionante y resolutorio retorno.

El papel de los medios de comunicación, potentes mecanismos de reconocimiento, refiguración y transmisión de memoria, es en este sentido central; ellos son hoy en las sociedades "occidentales", los "verdaderos intermediarios" —como dice Rémond (2002: 72) — entre la memoria privada y la memoria institucional. ¿Qué significados y qué consecuencias puede tener, entonces, el que la retórica "humanitaria" parezca recoger la historia de los "niños españoles" dentro de unos moldes (víctimas involuntarias, drama humano, papel del azar o el destino, énfasis en paradojas trágicas...) que la asemejan a los testimonios "singulares", "personales", "reales"... que los medios reproducen cuando abordan diversos problemas socio-históricos (inmigración, catástrofes naturales, hambrunas, epidemias, guerras, etc.), simplificán- 
dolos, homogeneizándolos y, generalmente, despolitizándolos? No está claro, en absoluto, que la ya muy extendida presentación espectacularizada de lo patético —la "patetización del mundo" de la que habla Fassin (1999)— signifique un novedoso restablecimiento de la narración y el intercambio de "experiencias". Posamos aún, en lo esencial, en el paisaje que describió Benjamin:

Con la [primera] guerra mundial comenzó a manifestarse un movimiento que hasta hoy nunca se ha detenido. ¿No se advirtió, durante la guerra, que la gente volvía muda del campo de batalla? No.más rica en experiencias transmisibles sino más pobre. Lo que, diez años después, se vertió en el caudal de los libros de guerra, era una cosa muy distinta a la experiencia que pasa de boca en boca (Benjamin 1970: 190).

Centradas en nudos dramáticos de tragedia "humana", llamadas a despertar adhesiones sentimentales fáciles (además de fugaces) o, en otros casos, a deleitar cierto esteticismo de los horrores y a evitar el restablecimiento de las complejidades de todo proceso histórico real, insertas en diseños de emisión o de publicación que trivializan sus contenidos, estas narrativas tienen muy pocas posibilidades de activar la reflexión y el aprendizaje que se le supone a la "experiencia".

Por añadidura, el asunto concierne al investigador social directamente, en tanto que la investigación misma es demandada en ocasiones, o es utilizada, en este proceso comunicativo. Las historias de vida elaboradas por sociólogos y antropólogos sociales forman parte, por ejemplo, de la oferta de memorias y de vidas en un mercado editorial volcado también sobre la producción-comunicación de testimonios "singulares", "personales" y "reales" (Lejeune 1994: 313 y ss.). El investigador no debe prescindir de una vigilancia y una meditación crítica permanente sobre los moldes retóricos que se ve impelido a adoptar, y sobre los efectos de lectura incontrolados que su trabajo puede suscitar. Quedar obnubilado por la novedad epistemológica del "paradigma narrativo" puede hacer que se olvide el funcionamiento socio-político de las narrativas como modos ideológicos de desmovilización, constricción y control social en diversos contextos de comunicación (Mumby 1997: 11-20). Y, desde luego, el trabajo del científico social debería evitar su contribución al mantenimiento de una imagen "simplista y unilateral" de los fenómenos y los problemas sociales, como la que habitualmente dan los media: una imagen "sensible y humanitaria" cuando las historias "reales" de las personas se ponen en juego en sus dramatizaciones espectacularizadas. El científico social debería avanzar hacia la imposición de una "representación compleja y múltiple" de aquellos fenómenos y de esas existencias personales, para lo que, como indica Bourdieu, si hay un estilo literario y unas retóricas intere- 
santes, son precisamente los de los novelistas que cuestionaron la narración tradicional, como Joyce, Faulkner o Woolf (Bourdieu 1999: 9).

Clifford afirma (1995: 119) que hablar de la constitución cultural del individuo es ya una especie de axioma. Probablemente haya que salvar de la irrelevancia y la rutinización la relación que establece el enunciado; trabajar, por ejemplo, sobre la idea de que esa representación cultural no es unitaria ni fija, que no da cuenta por sí misma de todo lo que está en juego en los procesos de producción socio-culturales de la subjetividad. Cuando se analizan los discursos autobiográficos como discursos retóricos en que la narración se reconoce pero no se toma como función unificadora — cuando no se los orienta hacia un texto que resume de modo coherente y sintético una vida-, el interés se vuelca sobre: diferentes modos de memoria en ejercicio, diferentes relaciones con los pasados y diferentes usos del tiempo. El objeto que el científico social se propone entonces no es la identidad narrativa ni el concepto cultural de persona ni la representación de sí mismo en una población, sino las problemáticas subjetivo-sociales, las situaciones en que a determinados agentes sociales se les plantea la problemática de su identidad y subjetividad. Este enfoque tiene consecuencias no sólo epistemológicas y metodológicas, sino también prácticas: obliga a mirar los problemas políticos planteados en torno a la memoria, y los imperativos éticos relativos a ésta, de manera diferente.

\section{BIBLIOGRAFÍA CITADA}

AUGÉ, MARC. 1998. Las formas del olvido. Barcelona: Gedisa.

BENJAMIN, WALTER. 1970. "El narrador. Consideraciones sobre la obra de Nicolai Leskov", en Sobre el programa de la filosofia futura, y otros ensayos: 189-211. Caracas: Monte Ávila.

BerTaUX, Daniel. 1997. Les récits de vie. Perspectives Ethnosociologiques. París: Nathan. BOURDIEU, PIERRE. 1982. Leçon sur la leçon. París: Minuit.

-. 1997. Razones prácticas. Barcelona: Anagrama.

-. 2001. Langage et pouvoir symbolique. París: Seuil.

BOURDIEU, PIERRE (ed.). 1999. La miseria del mundo. Madrid: Akal.

ClifFord, JAmes. 1995. Dilemas de la cultura. Barcelona: Gedisa.

Devillard, Marie-José; Álvaro Pazos, Susana Castillo y Nuria Medina. 2001. Los niños españoles en la URSS (1937-1997): narración y memoria. Barcelona: Ariel.

FASSIN, DIDIER. 1999. "La patetización del mundo. Ensayo de antropología política del sufrimiento", en M. Viveros Vigoya y G. Garay Ariza (eds.), Cuerpo, diferencias y desigualdades: 31-41. Santa Fé de Bogotá: Universidad Nacional de Colombia.

LEJEUNE, PHILIPPE. 1994. El pacto autobiográfico y otros estudios. Madrid: Endymion.

—. 1996. Le pacte autobiographique. París: Seuil. 
LeVI, Primo. 1989. Los bundidos y los salvados. Barcelona: Muchnick.

MuMBY, DeNNIS. 1997. "Introducción: narrativa y control social", en D. Mumby (comp.), Narrativa y control social. Perspectivas criticas: 11-25. Buenos Aires: Amorrortu.

MCLEAN, M. 1988. Narrative as Performance: The Baudelairean experiment. Londres: Routledge and Kegan Paul.

Páez, Darío; José F. Valencia, James W. Pennebaker, Bernard Rimé y Denise Jodelet (eds.). 1998. Memorias colectivas de procesos culturales y politicos. Bilbao: Universidad del País Vasco.

PASSERINI, L. 1992. Memory and Totalitarism. Oxford: Oxford University Press.

PAZOS, ÁlvARo. 2002. "El tiempo pasado. Formas discursivas y usos sociales del recuerdo". Estudios de Psicología 23 (1): :111-126.

Pontalis, Jean-Bertrand. 1997. Ce temps qui ne passe pas. París: Gallimard.

RÉMOND, RENÉ. 2002. "La transmisión de la memoria", en Academia Universal de las Culturas, ¿Por qué recordar?: 69-76. Barcelona: Granica.

Ricoevr, PAul. 2002. "Definición de la memoria desde un punto de vista filosófico", en Academia Universal de las Culturas, ¿Por qué recordar?: 24-28. Barcelona: Granica.

Rosa, Alberto; Guglielmo Bellelli y David BAKHurst (eds.). 2000. Memoria colectiva e identidad nacional. Madrid: Biblioteca Nueva.

SCHNAPPER, DOMINIQUE. 2002. "La memoria en la política", en Academia Universal de las Culturas, ¿Por qué recordar?: 76-80. Barcelona: Granica.

TODOROv. TzVETAN. 2000. Los abusos de la memoria. Barcelona: Paidós. 